\title{
Size does really matter
}

\author{
Sarah Kilbourne, $\mathrm{MD},{ }^{\mathrm{a}}$ and Alexander Sasha Krupnick, $\mathrm{MD}^{\mathrm{b}}$

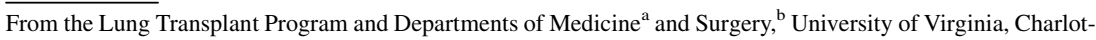 \\ tesville, Va. \\ Disclosures: Authors have nothing to disclose with regard to commercial support. \\ Received for publication Dec 1, 2017; accepted for publication Dec 4, 2017; available ahead of print Jan 17, 2018. \\ Address for reprints: Sarah Kilbourne, MD, Department of Medicine, Division of Pulmonary and Critical Care, \\ PO Box 800546, Charlottesville, VA 22908 (E-mail: skk2f@virginia.edu). \\ J Thorac Cardiovasc Surg 2018;155:1880-1 \\ $0022-5223 / \$ 36.00$ \\ Copyright $\subset 2017$ by The American Association for Thoracic Surgery \\ https://doi.org/10.1016/j.jtcvs.2017.12.030
}

Lung transplantation is a critical therapy for patients with end-stage lung disease. Yet with poor long-term survival of approximately $50 \%$ at 5 years, ${ }^{1,2}$ lung transplant recipients have the worst long-term outcomes of all solidorgan transplant recipients. There are several commonly agreed on recipient risk factors that associate with poor outcomes, namely, advanced age, renal dysfunction, and severity of pretransplant lung dysfunction. ${ }^{3}$ The evidence is less clear for other risk factors, including body mass index (BMI).

Although an often studied risk factor, the evidence of the impact of BMI on survival is conflicting. Lederer and colleagues ${ }^{4}$ found an increased mortality risk in patients who were underweight, overweight, or obese. Conversely, when using the same United Network for Organ Sharing database as Lederer and colleagues, ${ }^{4}$ Singer and colleagues ${ }^{5}$ found overweight and class I obese patients to have similar mortality risk when compared with individuals of normal weight. ${ }^{5}$ Aside from a need to sort out conflicting data that included pre-Lung Allocation Score era recipients, a precise understanding of the association between BMI and survival is useful because, unlike the aforementioned risk factors that are generally not modifiable, BMI is one risk factor that can be changed. In the contemporary Lung Allocation Score era, it has the potential to be a key component to optimize management of these patients.

Fernandez and colleagues, ${ }^{6}$ from Northwestern University Feinberg School of Medicine, take a straightforward, precise approach to assess the risk. Rather than using predefined BMI categories (eg, BMI $<18.5 \mathrm{~kg} / \mathrm{m}^{2}$ : below normal weight, BMI $>18.5 \mathrm{~kg} / \mathrm{m}^{2}$ and $<25 \mathrm{~kg} / \mathrm{m}^{2}$ : normal weight, BMI $>25 \mathrm{~kg} / \mathrm{m}^{2}$ and $<30 \mathrm{~kg} / \mathrm{m}^{2}$ overweight, BMI $>30 \mathrm{~kg} / \mathrm{m}^{2}$ and $<35 \mathrm{~kg} / \mathrm{m}^{2}$ class I obesity), they individualized each BMI unit to study the impact of BMI on survival at 90 days and 1 year. By using individual BMI units, they challenge the assumption that "normal weight" is associated with the best survivability post-transplant. Indeed, they demonstrate that BMIs of 25 and $26 \mathrm{~kg} / \mathrm{m}^{2}$ at the time of transplant were associated with the lowest

\section{References} 1):357-424.

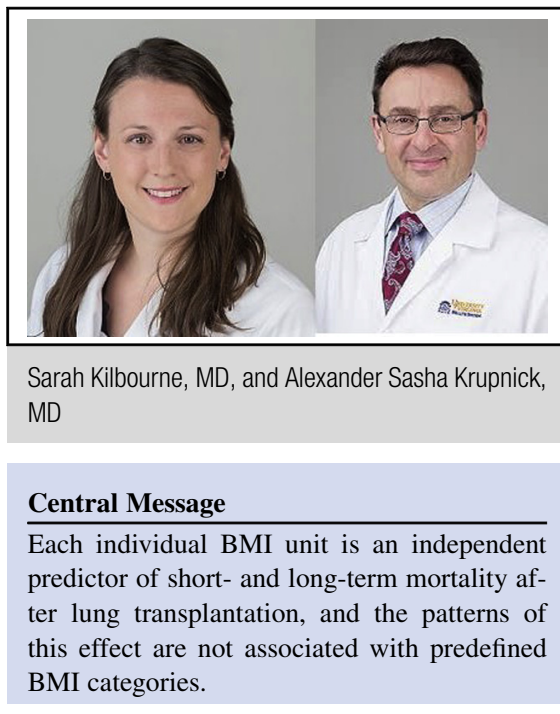

See Article page 1871.

probability of death at 90 days and 1 year, respectively. Along those same lines, which ignore traditional predefined BMI categories, recipient BMI $<20$ and $>28 \mathrm{~kg} / \mathrm{m}^{2}$ at the time of listing is an independently increased risk factor of both short- and long-term mortality. Furthermore, they found that each BMI unit has a unique risk for posttransplant mortality, suggesting that the patients within each BMI category are a heterogeneous group.

Improving lung transplant recipients' short- and longterm survival remains a challenging prospect. Assessing modifiable factors, like BMI, sheds light on recipient characteristics that can be a potential focus of intervention for preoperative candidate optimization. At the very least, it gives lung transplant clinicians another piece of data to have a more accurate expectation of survivability for their individual patients. Thus, size does really matter, and Fernandez and colleagues ${ }^{6}$ make the case that individualization of BMI units is "just right."

1. Lodhi SA, Lamb KE, Meier-Kriesche HU. Solid organ allograft survival improvement in the United States: the long-term does not mirror the dramatic short-term success. Am J Transplant. 2011;11:1226-35.

2. Valapour M, Skeans MA, Smith JM, Edwards LB, Cherikh WS, Uccellini K, et al. OTPN/SRTR 2015 Annual Data Report: Lung. Am J Transplant. 2017;17(Suppl

3. Russo MJ, Davies RR, Hong KN, Irbarne A, Kawut S, Bacchetta M, et al. Who is the high-risk recipient? Predicting mortality after lung transplantation using pretransplant risk factors. J Thorac Cardiovasc Surg. 2009;138:1234-8.e1.

4. Lederer DJ, Wilt JS, D'Ovidio F, Bacchetta MD, Shah L, Ravichandran S, et al. Obesity and underweight are associated with an increased risk of 
death after lung transplantation. Am J Respir Crit Care Med. 2009;180: 887-95.

5. Singer JP, Peterson ER, Snyder ME, Katz PP, Golden JA, D’ Ovidio F, et al. Body composition and mortality after adult lung transplantation in the United States. Am J Respir Crit Care Med. 2014;190:1012-21.
6. Fernandez R, Safaeinili N, Kurihara C, Odell DD, Jain M, DeCamp MM, et al. Association of body mass index with lung transplant survival in the United States following the implementation of the lung allocation score. J Thorac Cardiovasc Surg. 2018;155: 1871-9.e3. 